\title{
Fourier series in Differential Equations with GeoGebra
}

\author{
Jorge Olivares Funes ${ }^{1 *}$, Pablo Martín ${ }^{1}$ and Jose Rojo Lobos ${ }^{2}$ \\ ${ }^{1}$ University Antofagasta, Chile \\ ${ }^{2}$ Calama Future Corporation, Chile \\ *Corresponding Author
}

\begin{abstract}
.
In this work, the GeoGebra applets will be used to treat nonhomogeneous linear differential equations, wherein the nonhomogeneous part is a certain periodic function, piecewise constant, approximated by its Fourier series.

Several studies have already shown that the proper use of GeoGebra helps to learn and understand the mathematics. This is why this software as an important complement for learning differential equations.
\end{abstract}

Keywords: Aproximations, Differential equations, Fourier series, GeoGebra, Tics

\section{Introduction}

Today many researchers recommend the use of GeoGebra, as stated by Ronnys Jesús Vicent Millán, Fray Rafael de Dios Granados Pérez and Anner Luis Pariche Valdivieso in their work "Proposal for the teaching of learning polar coordinates with GeoGebra" [2], and Stephanie Díaz and Juan Luis Prieto, in "Visualization in the simulation with GeoGebra. an experience in reorganization of mathematical knowledge"[1]. In our case, based on these results and works, the GeoGebra applets are used to treat some nonhomogeneous linear differential equations as well as their solutions, wherein the nonhomogeneous part is a certain periodic function, piecewise constant, approximated by its Fourier series. What is shown in this work corresponds to the support material for teaching with GeoGebra as part of the teaching and learning process of the differential equations course for the engineering careers at the University of Antofagasta. This paper is an extension of "Resolving non-homogeneous linear differential equations using the undetermined method coefficients and variation of parameters by means of GeoGebra" [3].

\section{Differential equations and Fourier series with GeoGebra Applets}

He, the GeoGebra applets will be applied to linear second order differential equations with constant coefficients, including a non-homogeneous part. This will be a special periodic function with its Fourier series.

\section{info@icfte.com $14 \quad$ www.icfte.com}




\section{$4^{\text {th }}$ INTERNATIONAL CONFERENCE ON FUTURE OF TEACHING \& EDUCATION}

\section{Amsterdam, The Netherlands}

These applets are available publicly and free on Web

https://www.geogebra.org/m/skq7hxyg\#material/ft2vgrng

\section{Example 1}

$\mathrm{Be}$

$\frac{d^{2} y}{d x^{2}}-(\mathrm{a}+\mathrm{b}) \frac{d y}{d x}+a b y=\left\{\begin{array}{cl}k, & -k<x<0 \\ k, & 0<x<k\end{array}\right.$

where

$g(x)=\left\{\begin{array}{cl}k, & -k<x<0 \\ k, & 0<x<k\end{array} \quad, \quad \mathrm{~g}(x)=\mathrm{g}(x+2 \mathrm{k})\right.$

and "a" is changing between 0.1 and 2.5, "b" between 3 and 5, and " $\mathrm{k}$ " between (-8) and 8

The solution of this DE is: $\mathrm{y}=c_{1} e^{a x}+c_{2} e^{b x}+\frac{k}{a b}$

which it is shown in figure 1 graphically, and in algebraic form with blue color, between (-5) and 5, see c1 and c2.

The Fourier series of $\mathrm{g}(\mathrm{x})$ is the red line $\mathrm{y}=\mathrm{k}$, defined in its main branch $[-k, k]$.

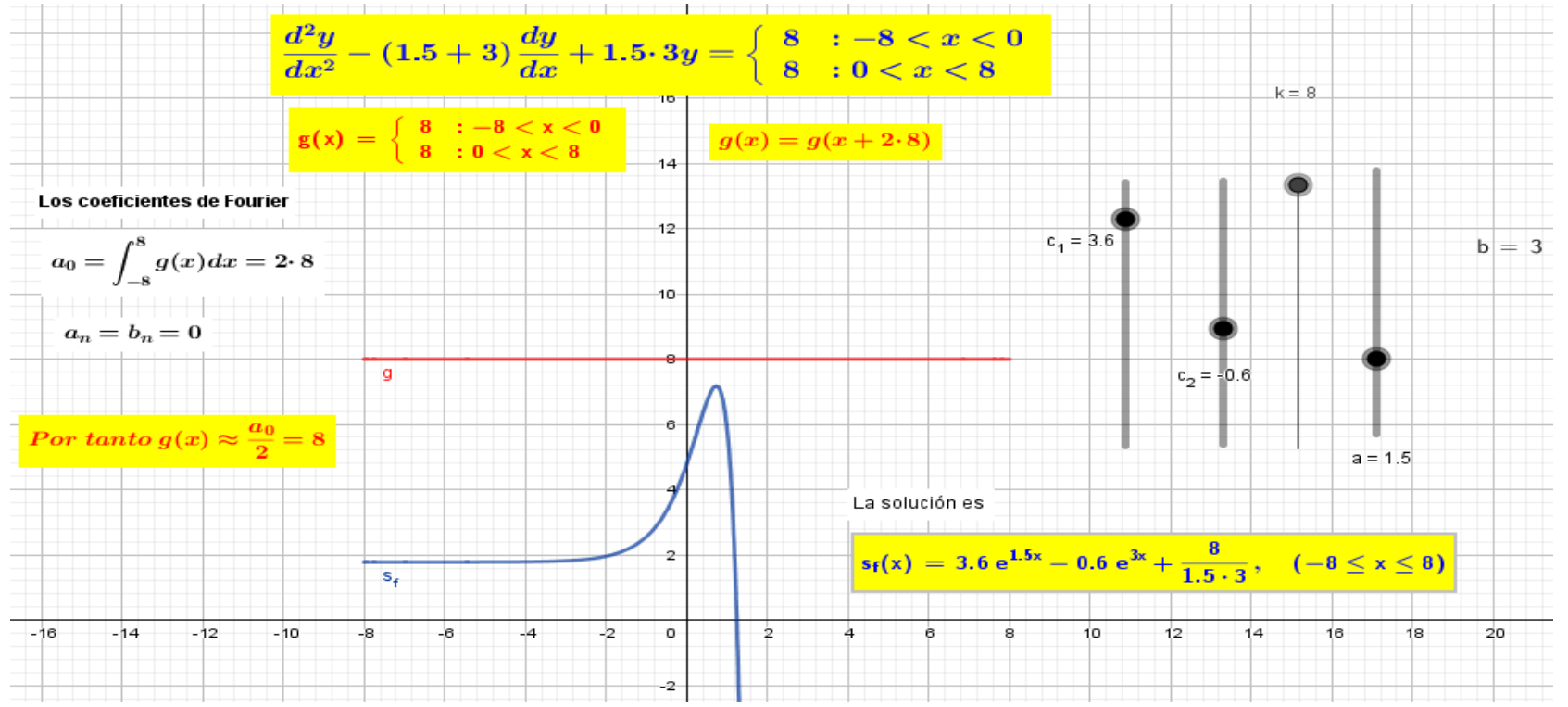

Figure 1 


\section{$4^{\text {th }}$ INTERNATIONAL CONFERENCE ON FUTURE OF TEACHING \& EDUCATION}

\section{Amsterdam, The Netherlands}

\section{Example 2}

$\mathrm{Be}$

$\frac{d^{2} y}{d x^{2}}-2 \mathrm{a} \cdot \frac{d y}{d x}+a^{2} y= \begin{cases}k, & -k<x<0 \\ k, & 0<x<k\end{cases}$

where

$g(x)=\left\{\begin{array}{cl}k, & -k<x<0 \\ k, & 0<x<k\end{array} \quad, \quad \mathrm{~g}(x)=\mathrm{g}(x+2 \mathrm{k})\right.$

"a" is moving between 0.1 and 5 , and " $\mathrm{k}$ " between (-8) and 8 .

The solution of this DE is: $\mathrm{y}=c_{1} e^{a x}+c_{2} x e^{a x}+\frac{k}{a^{2}}$

and it is shown grphiclly in figure 2, and in algebraic form with blue color, between (-5) and 5 , see $\mathrm{c} 1$ and $\mathrm{c} 2$.

The Fourier series of $\mathrm{g}(\mathrm{x})$ is the red line $\mathrm{y}=\mathrm{k}$, defined in its main branch $[-k, k]$.

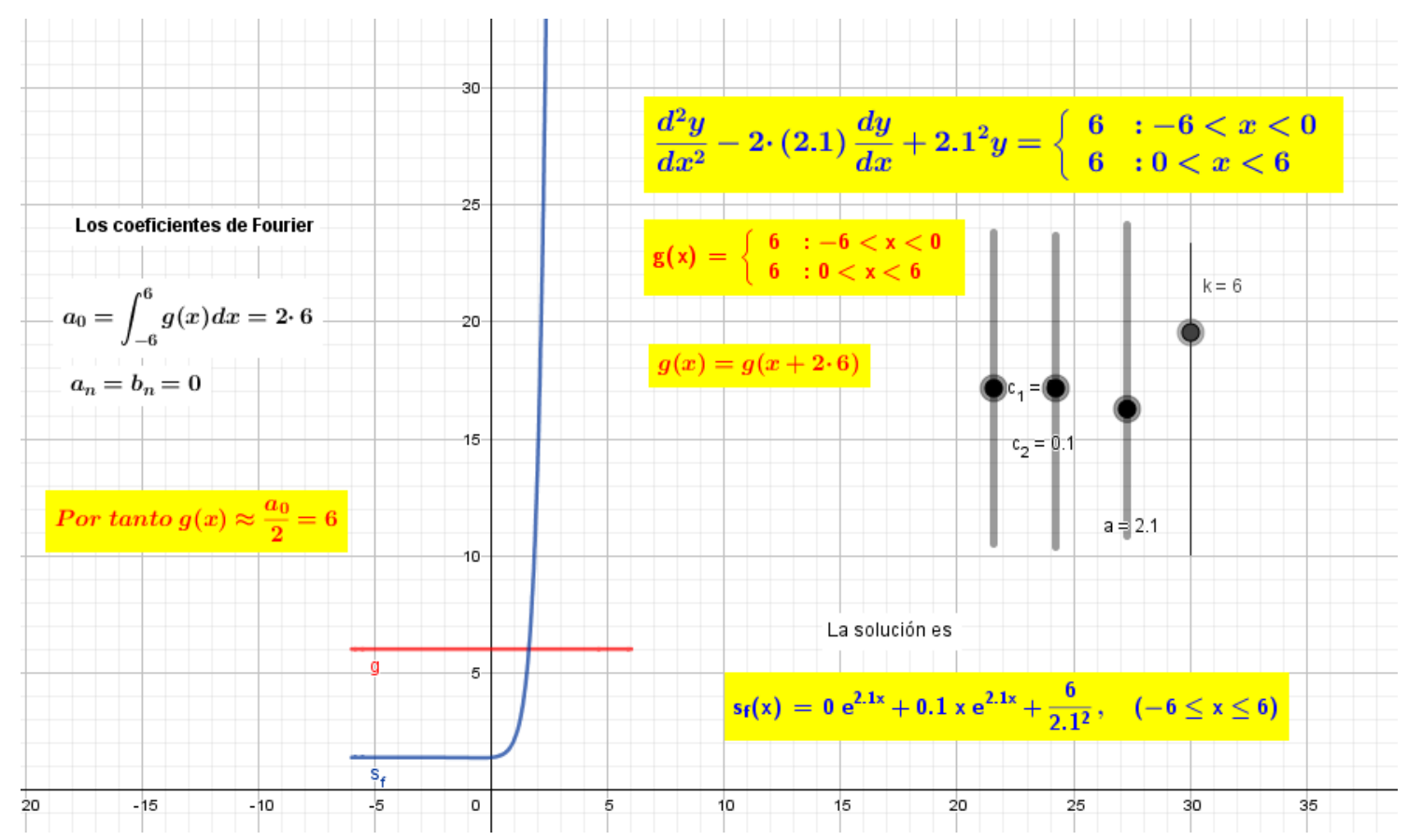

Figure 2 


\section{$4^{\text {th }}$ INTERNATIONAL CONFERENCE ON FUTURE OF TEACHING \& EDUCATION}

\section{Amsterdam, The Netherlands}

\section{Example 3}

$\mathrm{Be}$

$\frac{d^{2} y}{d x^{2}}-2 \mathrm{a} \cdot \frac{d y}{d x}+\left(a^{2}+b^{2}\right) y= \begin{cases}k, & -k<x<0 \\ k, & 0<x<k\end{cases}$

where

$g(x)=\left\{\begin{array}{cl}k, & -k<x<0 \\ k, & 0<x<k\end{array} \quad, \quad \mathrm{~g}(x)=\mathrm{g}(x+2 \mathrm{k})\right.$

and "a" is moving between 0.1 and 2.5, "b" between 3 and 5. and "k", between (-8) and 8

The solution of this DE is: $\mathrm{y}=c_{1} e^{a x} \cos (b x)+c_{2} e^{a x} \operatorname{sen}(b x)+\frac{k}{a^{2}+b^{2}}$

and it is represented in figure 3 graphically, and in algebraic form with blue color, between $(-5)$ and 5 , see $\mathrm{c} 1$ and $\mathrm{c} 2$.

The Fourier series of $\mathrm{g}(\mathrm{x})$ is the red line $\mathrm{y}=\mathrm{k}$, defined in its main branch $[-k, k]$. "a", "b" move between 0.1 and 5 and $\mathrm{k}$ between -8 and 8 .

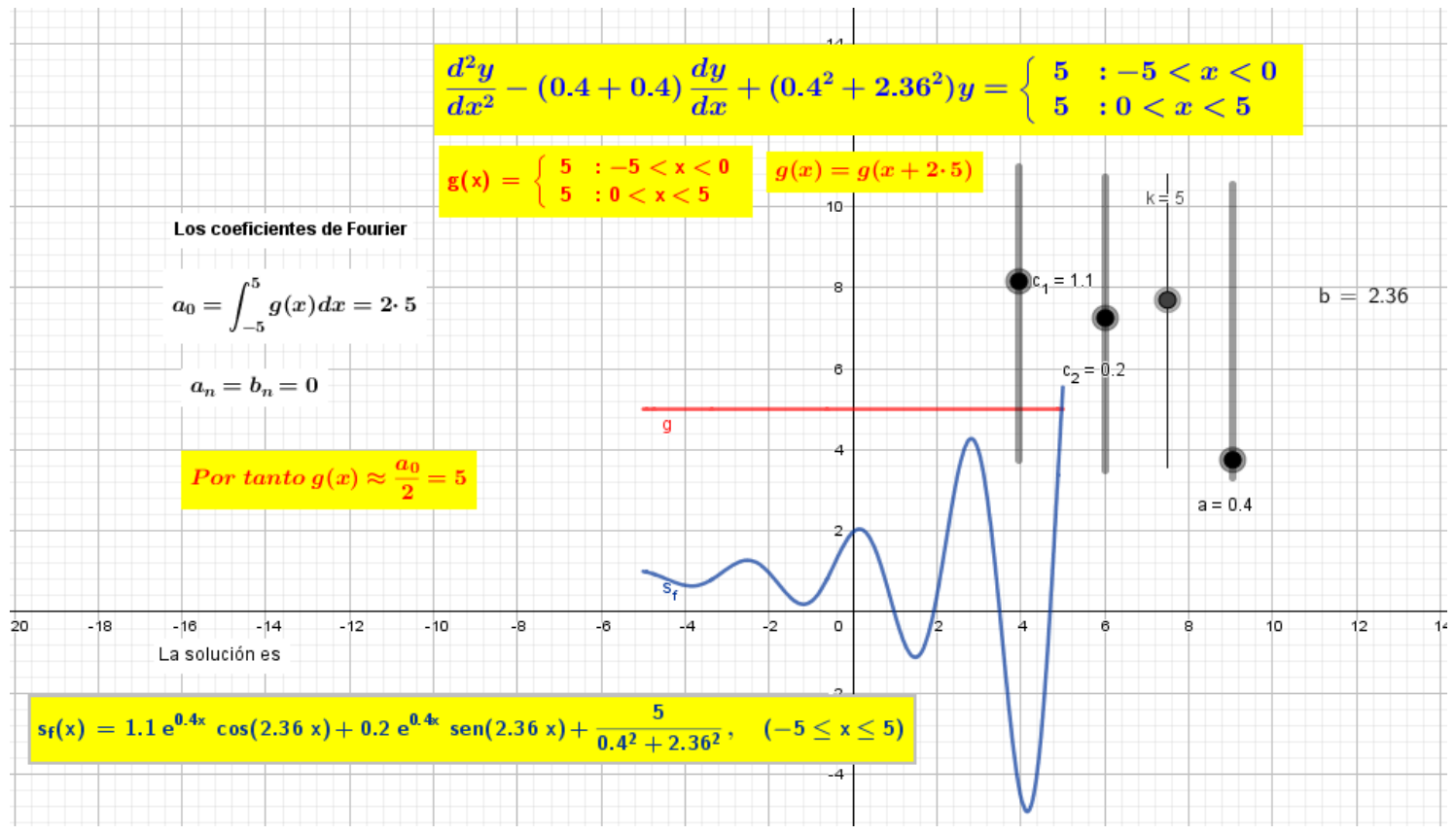

Figure 3 


\section{$4^{\text {th }}$ INTERNATIONAL CONFERENCE ON FUTURE OF TEACHING \& EDUCATION}

\section{Amsterdam, The Netherlands}

$16-18$ July 2021

\section{Conclusion}

It is shown that the GeoGebra applets is great tool for teaching and to help the student. This allows us to fulfill the task of visualizing differential equations with their very special Fourier solutions and series.

The purpose of this work has been to share and to encourage the use of GeoGebra in the different courses of higher mathematics education as well as an aid in the significant learning. especially of the DE. There are also a great applicability in other different areas of science and engineering.

\section{References}

Díaz, Stephanie; Prieto, Juan Luis . Visualización en la simulación con GeoGebra. Una experiencia de reorganización del conocimiento matemático. In Serres, Yolanda; Martínez, Angélica; Iglesias, Martha; León, Nelly (Eds.), IX Congreso Venezolano de Educación Matemática (pp. 223-231). Barquisimeto: ASOVEMAT. (2016).

Ronnys Jesús Vicent Millán, Fray Rafael de Dios Granados Pérez, Anner Luis Pariche Valdivieso , "Propuesta para la enseñanza/aprendizaje de las coordenadas polares con GeoGebra “ , XV CIAEM-IACME, Medellín, Colombia, 2019. XV CIAEM-IACME, Medellín, Colombia, (2019).

Jorge Olivares Funes and Elvis Valero Kari , "Resolving non-homogeneous linear differential equations using the undetermined method coefficients and variation of parameters by means of GeoGebra “. 2019 J. Phys.: Conf. Ser.1391 012057 